\title{
In-situ tube burst testing and high-temperature deformation behavior of candidate materials for accident tolerant fuel cladding
}

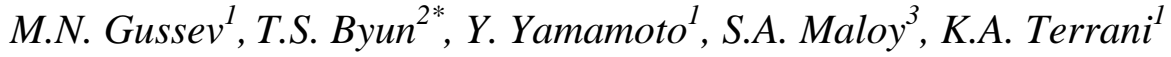 \\ 1. Oak Ridge National Laboratory, Oak Ridge, TN 37831, USA \\ 2. Pacific Northwest National Laboratory, Richland, WA 99352, USA \\ 3. Los Alamos National Laboratory, Los Alamos, NM 87545, USA
}

\begin{abstract}
One of the most essential properties of accident tolerant fuel (ATF) for maintaining structural integrity during a loss-of-coolant accident (LOCA) is high resistance of the cladding to plastic deformation and burst failure, since the deformation and burst behavior governs the cooling efficiency of flow channels and the process of fission product release. To simulate and evaluate the deformation and burst process of thin-walled cladding, an in-situ testing and evaluation method has been developed on the basis of visual imaging and image analysis techniques. The method uses a specialized optics system consisting of a high-resolution video camera, a light filtering unit, and monochromatic light sources. The in-situ testing is performed using a $50 \mathrm{~mm}$ long pressurized thin-walled tubular specimen set in a programmable furnace. As the first application, ten (10) candidate cladding materials for ATF, i.e., five FeCrAl alloys and five nanostructured steels, were tested using the newly developed method, and the timedependent images were analyzed to produce detailed deformation and burst data such as true hoop stress, strain (creep) rate, and failure stress. Relatively soft FeCrAl alloys deformed and burst below $800^{\circ} \mathrm{C}$, while negligible strain rates were measured for higher strength alloys.
\end{abstract}

\section{Keywords:}

Accident tolerant fuel (ATF), ATF cladding materials, in-situ tube burst testing, non-contact optic measurement, high temperature deformation.

\section{*Corresponding author:}

Thak Sang Byun

Pacific Northwest National Laboratory, 902 Battelle Boulevard, Richland, WA 99352, USA

Tel: 509-371-6490, Email: thaksang.byun@pnnl.gov 


\section{Introduction}

In both normal operation and accident conditions, the fuel cladding is the most critical core structure in fission reactors because it is subjected to extreme conditions but has to function as the first safety barrier [1-3]. A fuel cladding material is selected considering a variety of aspects such as neutron absorption cross section, mechanical strength and ductility, irradiation and thermal creep resistance, resistance to embrittlement, thermal expansion and conductivity, and chemical compatibility [2-4]. In light of the Fukushima Daiichi accident, however, demonstrating an improved level of accident tolerance is emphasized in the assessment of fuel performance, and a number of candidate materials and coatings are being studied to develop cladding materials with enhanced accident tolerance capacity [5,6]. Cladding behavior governs the cooling efficiency of flow channels and the process of fission product release; hence, during a loss-of-coolant accident (LOCA), the most important property of fuel cladding might be the resistance of the cladding material to plastic deformation and burst at high temperatures. Therefore, the key benchmarking properties for demonstrating accident tolerance should include the deformation-to-burst behavior of tubular specimens in a LOCA condition.

Traditionally, tube burst testing using high-pressure gas has been performed to measure the burst temperature as a function of internal pressure and to assess the performance of new and irradiated cladding specimens [7-14]. Typically a $\sim 30 \mathrm{~cm}$ (1 foot) long tubular specimen is employed in such tube burst testing [14]. It has been realized, however, that the efforts to develop and assess new accident tolerant fuel (ATF) cladding candidates in a short time period require obtaining both the basic material property data and the structural (or cladding) performance data in a limited time. Therefore, to experimentally simulate the cladding behavior during severe accidents, there has been a demand to develop a more efficient testing and evaluation methodology to obtain those property and structural performance data simultaneously. Ideally, a new method can be combined with cost-efficient irradiation experiments to comply with the demand for collection of a larger variety of data during pre- and post-irradiation deformation-burst tests. This research aimed to establish a new testing and evaluation method for simulating cladding behavior in accident conditions and to comparatively assess the performance of new cladding candidates. 
Recently, a new deformation-burst testing method was pursued to provide in-situ hightemperature deformation data as well as the traditional burst pressure-temperature data [15]. In particular, the in-situ cladding deformation record can provide creep rate and true wall stress data, which are essential in the assessment of fuel performance under LOCA conditions. It was also considered that the advancement of LOCA analysis tools like three-dimensional (3D) finite element modeling [16] may require additional detailed data, such as creep rate, under biaxial loading over the whole temperature range of the simulated accident. In the present research, therefore, a new high-temperature testing technology using pressurized thin-walled tubular specimens has been developed: a computer-controlled high-resolution camera with a filtering system has been used to obtain the in-situ deformation and burst data under simulated accident conditions. This article intends to provide enough information to allow other researchers to use the technology and to compare the starkly different responses of materials to a simulated condition.

The application experiment carried out in this research was intended to produce detailed in-situ mechanical property data for prospective ATF cladding materials. High-temperature tube deformation testing was performed for ten candidate ATF cladding materials. Among the test specimens were pressurized thin-walled tube specimens of $\mathrm{FeCrAl}$ alloys, oxide dispersion strengthened (ODS) FeCrAl alloys, and nanostructured ferritic alloys (NFAs), i.e., 14YWT and 9YWTV. For the relatively soft FeCrAl materials, the process of plastic deformation and burst

ended below $800^{\circ} \mathrm{C}$ and the plastic (creep) strain and strain rate up to the burst temperature were calculated. The higher strength alloys, on the other hand, showed little change in diameter and did not fail before the system limit temperature of $\sim 1100^{\circ} \mathrm{C}$ was reached.

\section{In-situ deformation and burst testing system}

\subsection{Background on high-temperature imaging}

The main goal of the imaging-based deformation measurement system is to perform insitu observation and recording of high-temperature deformation and burst while a tubular specimen is exposed to a simulated accident condition. The images of deforming tubes can be easily converted into dimensional data (during or after a test) and then into hoop strain values, from which one can calculate creep strain rate, failure strain, and true stress at the wall. The 
image recording will also enable precise detection of the deformation initiation temperature. Another benefit of using an image recording system is that simultaneous dimensional measurements at multiple positions can be pursued with an affordable programming effort.

In preparation for the present research, previous dimension measurement methods were reviewed to adopt the best practices of existing optical techniques. Video cameras have become affordable for dimensional measurements, even ones with high resolution and high data transfer rate. The most common method of optical measurement is using digital image correlation (DIC) to provide precise strain analysis and displacement measurement; for instance, high-pressure burst testing was performed on tubes made of composite fiber-reinforced silicon carbide [17]. Full-field strain analysis has been conducted using 3D DIC, and an acoustic emission technique was used to detect damage events during high-pressure burst testing. Lyons et al. [18] conducted high-temperature deformation measurement using DIC, in which the highest temperature was $650^{\circ} \mathrm{C}$ and no light filters or special light sources were used. Lately, new methods for hightemperature strain measurement using band-pass filters and short-wave illumination have been developed, and such techniques have been used at $1000^{\circ} \mathrm{C}$ and higher [19-21]. Full-field thermal deformation and thermal expansion coefficients for an austenitic stainless steel were determined up to $1200^{\circ} \mathrm{C}$ to demonstrate the workability of the method [20]. Further development in imaging techniques has shown that a technique of clustering cameras can help obtain a full 3D geometry of an object [22], and an extended high-temperature DIC method employing ultraviolet (UV) lights and special UV optics almost completely eliminated the light emitted by high-temperature specimens [23].

Another technique for high-temperature imaging is using the difference in emission wavelengths between materials. Guo et al. [23] assembled special high-temperature DIC equipment capable of working up to $2600^{\circ} \mathrm{C}$, which was using the difference in high-temperature emission spectra between carbon and tungsten that formed a speckle pattern on specimens. That is, since the intensity of thermal radiation from tungsten at high temperature is far below that from carbon, a reliable contrast can be produced to provide DIC measurement. 


\subsection{Imaging device and optics arrangement}

An algorithm based on image analysis technology was developed in the present research to detect and track the selected points, so that a personal computer can simultaneously perform video streaming and concurrent data processing at multiple points during temperature ramping. Further, specific techniques based on those used in the aforementioned studies were adopted and modified for the present tube burst testing. The first issue in high-temperature testing was the steep temperature gradient that may lead to severe air convection [18], particularly near the observatory windows where lenses are closely spaced. Since the index of refraction of light is sensitive to the temperature of matter, it could affect image stability and thus decrease the precision of dimensional measurements. In this research, the influence of convection was effectively suppressed by running small fans at the outer protective glass of view windows and by installing multiple protective glass sheets to form multiple air layers. However, it was not possible to fully eliminate the air convection and steep temperature gradient within the short distance between the lenses and filters and the furnace window (several centimeters). Also, all windows were made of high-quality optical glasses.

The second issue was the intense thermal radiation at elevated temperature, which usually causes faint and blurry images. As furnace temperature increases, the maximum intensity of thermal emission shifts from the infrared band to the visible light band. When the visible light signal becomes strong, the image quality decreases drastically below about $800^{\circ} \mathrm{C}$. A known technique is to replace the thermal radiation with its broad wavelength band with a light beam with near-single wavelength [19-21]. A similar but simplified technique was used in the present work: to form clear specimen images in the camera, the wavelengths emitted from heated furnace internals are almost completely removed by using a set of filters attached to the camera lens, and two monochromatic blue light sources are used to illuminate the specimens in the furnace. Those two light sources are installed on the front door of the furnace and illuminate the specimen through two windows. The intensity of blue light was adjusted to maximize sharpness at the edges of specimen images since the strain and creep rate calculations required accurate measurements of tube diameters [24].

A view of the camera-light-source system is shown in Figure 1(a). Details of the camera and optical components are as follows. The Prosilica GX 6600 digital charge-coupled device 
(CCD) camera with a low-noise, 29 megapixel CCD sensor was chosen for high-resolution imaging. This sensor can be operated at a frame rate of $\sim 10$ per second at the maximum resolution. The Macro-Symmar 5.6/120 lens in the common F-type mount used in this system provides high-quality imaging with uniform brightness and minimal distortion. The sensor-lens assembly has a resolution of $\sim 14-15 \mu \mathrm{m}$ per pixel.

Also attached to the lens are light filters transmitting only wavelengths between 450 and $470 \mathrm{~nm}$. These filters were selected not only because the CCD camera used has maximum sensitivity at a wavelength of $\sim 470 \mathrm{~nm}$, but also because the thermal emission from heated components is negligible at this wavelength below $1100^{\circ} \mathrm{C}$. High brightness light-emitting diode (LED) spotlights with $\sim 460 \mathrm{~nm}$ wavelength (blue color) were chosen to illuminate in-furnace objects and provide clear specimen visibility. Laboratory-written software was used to control the camera and video recording, and to measure the specimen diameter both in- and ex-situ during the experiment.

\subsection{Integrating imaging system with furnace}

ThermCraft, Inc., fabricated a custom furnace with windows for viewing and light sources by redesigning a commercial furnace model to accommodate the data collection optics and high-quality lighting conditions. As seen in 1(a), the front door of furnace has three windows: the central one is a viewing window for the CCD camera and the other two are for transmitting light beams onto the specimen set in the furnace chamber. The central aperture is an opening with a diameter of $50 \mathrm{~mm}$, in which a five-layer high-quality quartz window with an interlayer spacing of $8 \mathrm{~mm}$ is installed to reduce interlayer temperature differences and air convection. In addition, a set of sliding shutters is used to minimize unnecessary heating and thermal impact on the camera lens and other components. The illumination channels have four

protective glass plates and a special heat-resistant lens that provides the required divergence and scattering of the light. 

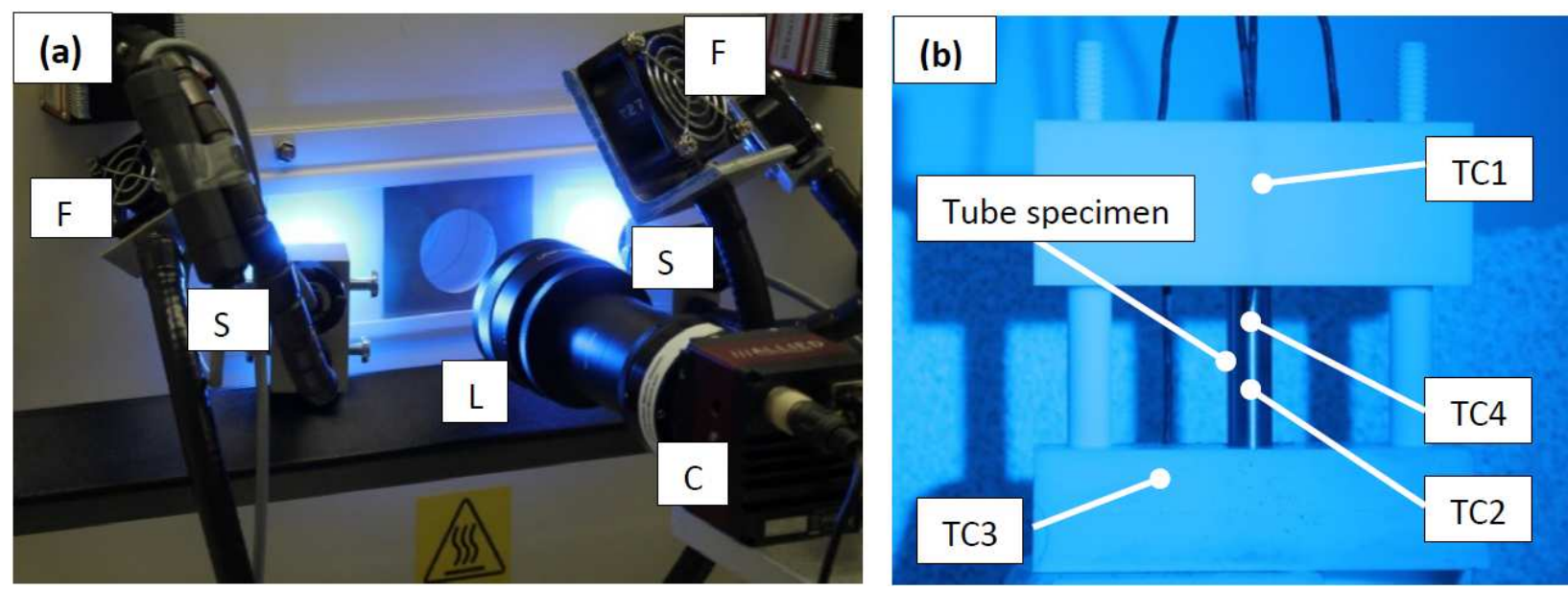

Figure 1. (a) Configuration of the system: C - camera, L - lens, S - light source, and F - cooling fan; (b) Ceramic specimen holder in the furnace. Four thermocouples are used (TC1-TC4); TC2 and TC4 are used in measuring the temperature of the specimen. The tube specimen shown has nominal dimensions of $9.5 \mathrm{~mm}$ outer diameter, $50 \mathrm{~mm}$ length, and $0.5 \mathrm{~mm}$ thickness.

A specimen holder was designed by taking into account the specimen geometry, the furnace geometry, specimen-to-specimen dimensional variations, and the dimensional changes during heating. The specimen holder shown in Figure 1(b), which is made of MACOR ${ }^{\circledR}$ ceramic, consisted of the base plate, two supporting rods, and a movable top beam to accommodate the specimen thermal expansion. The base plate and top beam have cone-shaped holes to accept specimens with different diameters and hold them vertically straight. These also have a set of holes for thermocouples.

One of the key issues in designing the present experiment was recording temperature, since the temperature ramping was not near steady-state heating and large differences between control temperature and local specimen temperature, as well as within the specimen holder assembly, were detected. To reduce errors in temperature data, temperature readings from multiple locations were recorded using a multichannel temperature controller/processing unit (NI cDAQ-9171 temperature controller). This controller processes signals from up to four thermocouples, shown in Figure 1(b). The two thermocouples marked TC1 and TC3 were used to monitor the temperatures of the specimen holder and the other two (TC2 and TC4) to monitor specimen temperature. 


\section{Materials and specimens}

A set of candidate ATF cladding materials was acquired and tested; their chemical compositions and final processing treatments are summarized in Table 1. The first five alloys belong to the group of $\mathrm{FeCrAl}$ alloys, which usually have excellent oxidation resistance at high temperatures and are considered the primary candidate cladding materials for ATFs. The next two materials, D155 series alloys, are advanced ODS alloys with FeCrAl alloy compositions. The last three alloys are also advanced ODS alloys, but belong to the NFA group without measurable $\mathrm{Al}$ content. The tubes of these materials were produced through either the traditional tube drawing process or mechanical machining (i.e., gun drilling and grinding). Since no tube processing technology is available at the moment for the advanced ODS alloys and strengthened $\mathrm{FeCrAl}$ alloys, the tubular specimens for these hard alloys were machined from thick plates or coupons. Table 1 summarizes the final treatments of those test materials; note that the tube processing is a complex and factory-specific treatment and its details are not known.

Table 1 . The chemistry and final processing of test materials

\begin{tabular}{|c|c|c|c|}
\hline $\begin{array}{l}\text { Materials } \\
\text { Group }\end{array}$ & Alloy & Composition (wt.\%) & Final Process \\
\hline \multirow{5}{*}{$\begin{array}{l}\text { FeCrAl } \\
\text { Alloy }\end{array}$} & Kanthal-AF & $\begin{array}{l}\text { Fe-21.2C-5Al-0.15Mn- } \\
0.19 \mathrm{Si}-0.027 \mathrm{C}-0.019 \mathrm{~N}\end{array}$ & $\begin{array}{l}\text { Processed for tubing, seam welding } \\
\text { followed by tube processing }\end{array}$ \\
\hline & $\mathrm{T} 35 \mathrm{Y}$ & $\mathrm{Fe}-13.2 \mathrm{Cr}-4.4 \mathrm{Al}-0.07 \mathrm{Y}$ & $\begin{array}{l}\text { Extruded at } 950^{\circ} \mathrm{C}+\text { annealed at } \\
700^{\circ} \mathrm{C} \text {, machined from rod }\end{array}$ \\
\hline & C35MN5 & $\begin{array}{l}\text { Fe-13Cr-5.1Al-2Mo- } \\
1 \mathrm{Nb}-0.2 \mathrm{Si}-0.03 \mathrm{Y}\end{array}$ & $\begin{array}{l}\text { Extruded at } 800^{\circ} \mathrm{C}+\text { annealed at } \\
800^{\circ} \mathrm{C} \text {, machined from rod }\end{array}$ \\
\hline & C35MN6 & $\begin{array}{l}\text { Fe-13Cr-5.1Al-2Mo- } \\
1 \mathrm{Nb}-0.2 \mathrm{Si}-0.04 \mathrm{Y}\end{array}$ & $\begin{array}{l}\text { Extruded at } 1200^{\circ} \mathrm{C}+\text { annealed at } \\
800^{\circ} \mathrm{C} \text {, machined from rod }\end{array}$ \\
\hline & $\mathrm{T} 35 \mathrm{Y} 2$ & $\mathrm{Fe}-13.2 \mathrm{Cr}-4.4 \mathrm{Al}-0.12 \mathrm{Y}$ & $\begin{array}{l}\text { Extruded at } 1050^{\circ} \mathrm{C}+\text { annealed at } \\
700^{\circ} \mathrm{C} \text {, tube processing }\end{array}$ \\
\hline \multirow{2}{*}{$\begin{array}{l}\text { Advanced } \\
\text { ODS } \\
\text { FeCrAl } \\
\text { Alloy }\end{array}$} & D155YT & $\begin{array}{l}\text { Fe-14.57Cr-4.7Al- } \\
0.44 \mathrm{Ti}-0.3 \mathrm{Y}_{2} \mathrm{O}_{3}\end{array}$ & $\begin{array}{l}\text { Consolidation-extruded at } 850^{\circ} \mathrm{C} \text {, hot- } \\
\text { rolled at } 1000^{\circ} \mathrm{C} \text {, machined from plate }\end{array}$ \\
\hline & D155YMT & $\begin{array}{l}\mathrm{Fe}-14.55 \mathrm{Cr}-4.75 \mathrm{Al}- \\
0.44 \mathrm{Ti}-0.88 \mathrm{Mo}-0.3 \mathrm{Y}_{2} \mathrm{O}_{3}\end{array}$ & $\begin{array}{l}\text { Consolidation-extruded at } 850^{\circ} \mathrm{C} \text {, hot- } \\
\text { rolled at } 1000^{\circ} \mathrm{C} \text {, machined from plate }\end{array}$ \\
\hline \multirow{3}{*}{$\begin{array}{l}\text { Advanced } \\
\text { ODS Fe-Cr- } \\
\text { W Alloy } \\
\text { (NFA) }\end{array}$} & 9YWTV-PM1 & $\begin{array}{l}\mathrm{Fe}-8.9 \mathrm{Cr}-2 \mathrm{~W}-0.35 \mathrm{Ti}- \\
0.18 \mathrm{~V}-0.11 \mathrm{C}-0.3 \mathrm{Y}_{2} \mathrm{O}_{3}\end{array}$ & $\begin{array}{l}\text { Consolidation-extruded at } 850^{\circ} \mathrm{C}, \\
\text { machined from coupon }\end{array}$ \\
\hline & 9YWTV-PM2 & $\begin{array}{l}\text { Fe-9.9Cr-2W-0.37Ti- } \\
0.18 \mathrm{~V}-0.06 \mathrm{C}-0.3 \mathrm{Y}_{2} \mathrm{O}_{3}\end{array}$ & $\begin{array}{l}\text { Consolidation-extruded at } 850^{\circ} \mathrm{C}, \\
\text { machined from coupon }\end{array}$ \\
\hline & 14YWT-CRT & $\begin{array}{l}\mathrm{Fe}-14 \mathrm{Cr}-2 \mathrm{~W}-0.4 \mathrm{Ti}- \\
0.3 \mathrm{Y}_{2} \mathrm{O}_{3}\end{array}$ & $\begin{array}{l}\text { Consolidation-extruded at } 850^{\circ} \mathrm{C} \text {, hot- } \\
\text { rolled at } 1000^{\circ} \mathrm{C} \text {, machined from plate }\end{array}$ \\
\hline
\end{tabular}


Endcaps for respective tubes were fabricated from the same materials and laser beamwelded to the both ends of those tubes in the pressurized chamber of the welding machine. One of the two endcaps used for each specimen had a hole with a $<0.5 \mathrm{~mm}$ diameter and was sealed after the tube was pressurized with helium gas to a target pressure in the welding chamber. Two T35Y2 specimens were tested, with (A-T35Y2) and without (B-T35Y2) gas pressurization. All specimens but B-T35Y2 were pressurized in the laser welding chamber to $0.3 \mathrm{ksi}(2.07 \mathrm{MPa})$ at room temperature. Note that this internal pressure will increase with temperature, obeying the gas law, but will not be linearly proportional to the furnace temperature if the tube balloons by deformation. After pressurization and welding, leak testing in water was performed for all welded specimens. Images of a typical specimen before after test are shown in Figure 2.

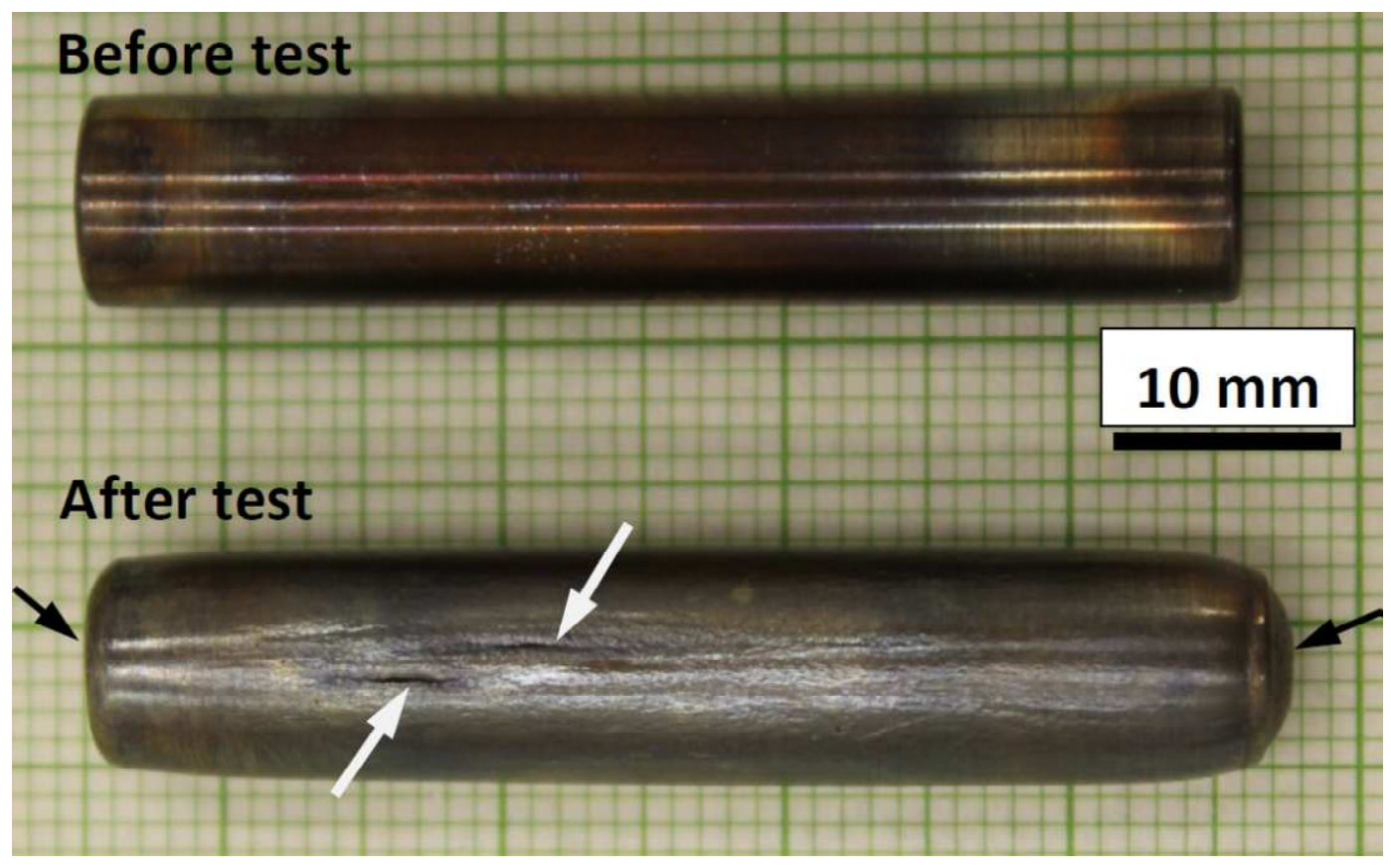

Figure 2. Pressurized tube specimens before (top) and after (bottom) burst test (T35Y alloy). Through-thickness cracks are marked by white arrows and the deformation of endcaps by black arrows. It is not known which opening has occurred first. 


\section{Results and discussion}

\subsection{Analysis procedure for a tube burst experiment}

The present work aimed to measure the specimen diameter change in-situ with simultaneous specimen temperature recording. This section provides experimental steps, images, and typical data reading and processing for a pressurized tube specimen test. In particular, a detailed analysis example is given for a typical pressurized specimen of a $\mathrm{FeCrAl}$ alloy of T35Y.

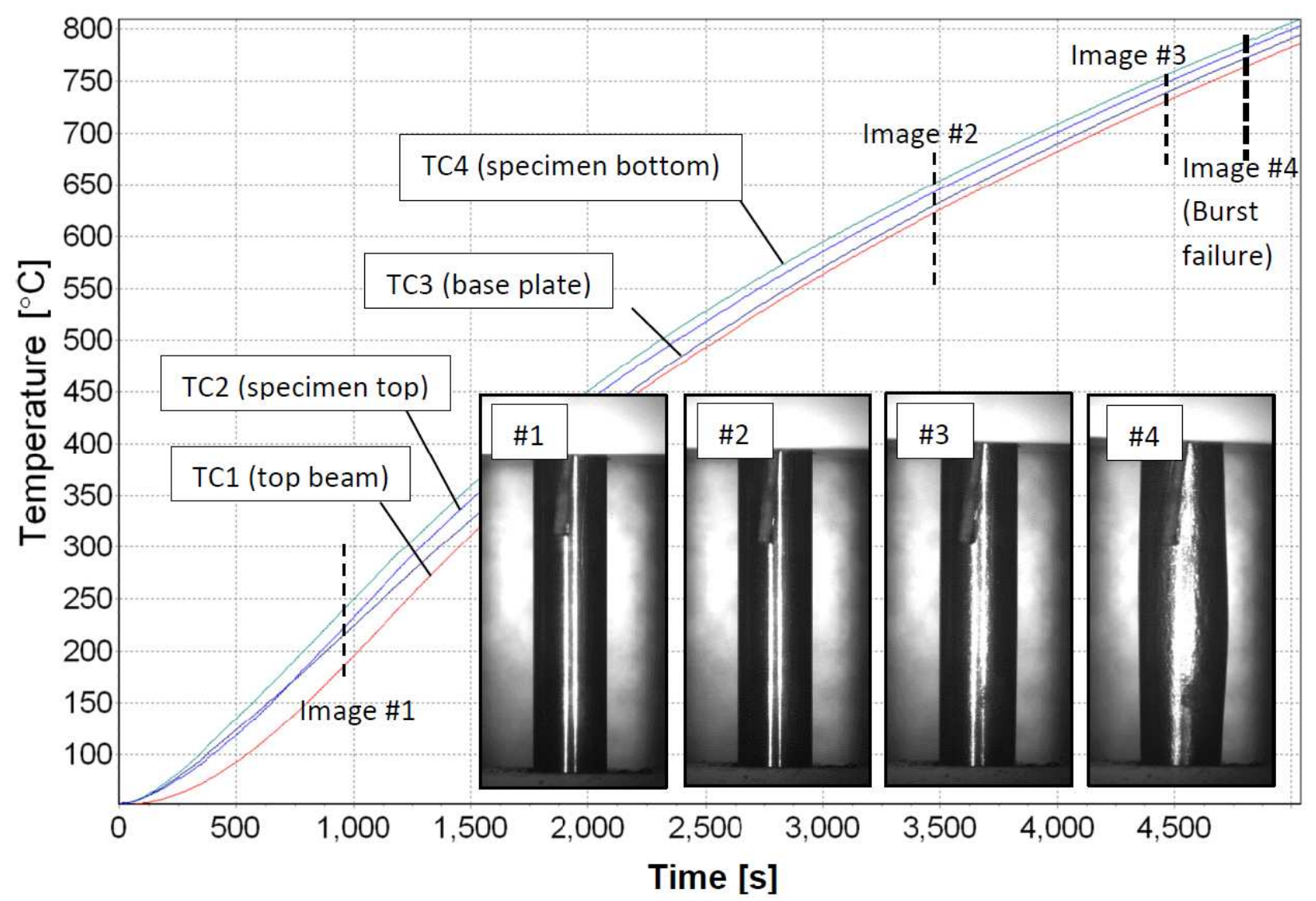

Figure 3. Typical thermocouple readings varying with time (for T35Y alloy). The dashed bold line indicates the burst of the pressurized tubular specimen. Positions marked with dotted lines correspond to images \#1 to \#4.

Figure 3 shows typical temperature responses versus time: the curves indicate that the temperatures at all thermocouple locations increase quite monotonically until significant ballooning or final burst occurs. The final failure usually is caused by formation of a small leak 
crack near the maximum diameter area. As indicated in the temperature-versus-time curves, it was not possible to keep a constant temperature ramping rate because of the furnace characteristics. Although the furnace control can heat up at a constant rate (e.g., $10{ }^{\circ} \mathrm{C} / \mathrm{min}$ ), there always was some difference between the furnace temperature setting and the actual specimen temperature because of the thermal inertia of the test components. The resulting temperature ramping rate was in the range of $5-15^{\circ} \mathrm{C} / \mathrm{min}$, and at $800^{\circ} \mathrm{C}$ where the burst failure occurred, for example, the heating rate was close to $6{ }^{\circ} \mathrm{C} / \mathrm{min}$. It is also apparent in Figure 3 that there exist small differences among thermocouple readings: the thermocouples located in the specimen holder, which are marked as TC1 and TC3 in Figure 1b, always displayed lower temperatures than the specimen thermocouples, i.e., TC2 and TC4. The difference reached 30$50^{\circ} \mathrm{C}$ at low temperatures $\left(<200^{\circ} \mathrm{C}\right)$ but decreased to a smaller but consistent gap of $15-20^{\circ} \mathrm{C}$ or less when the specimen entered the plastic deformation mode above $\sim 550^{\circ} \mathrm{C}$.

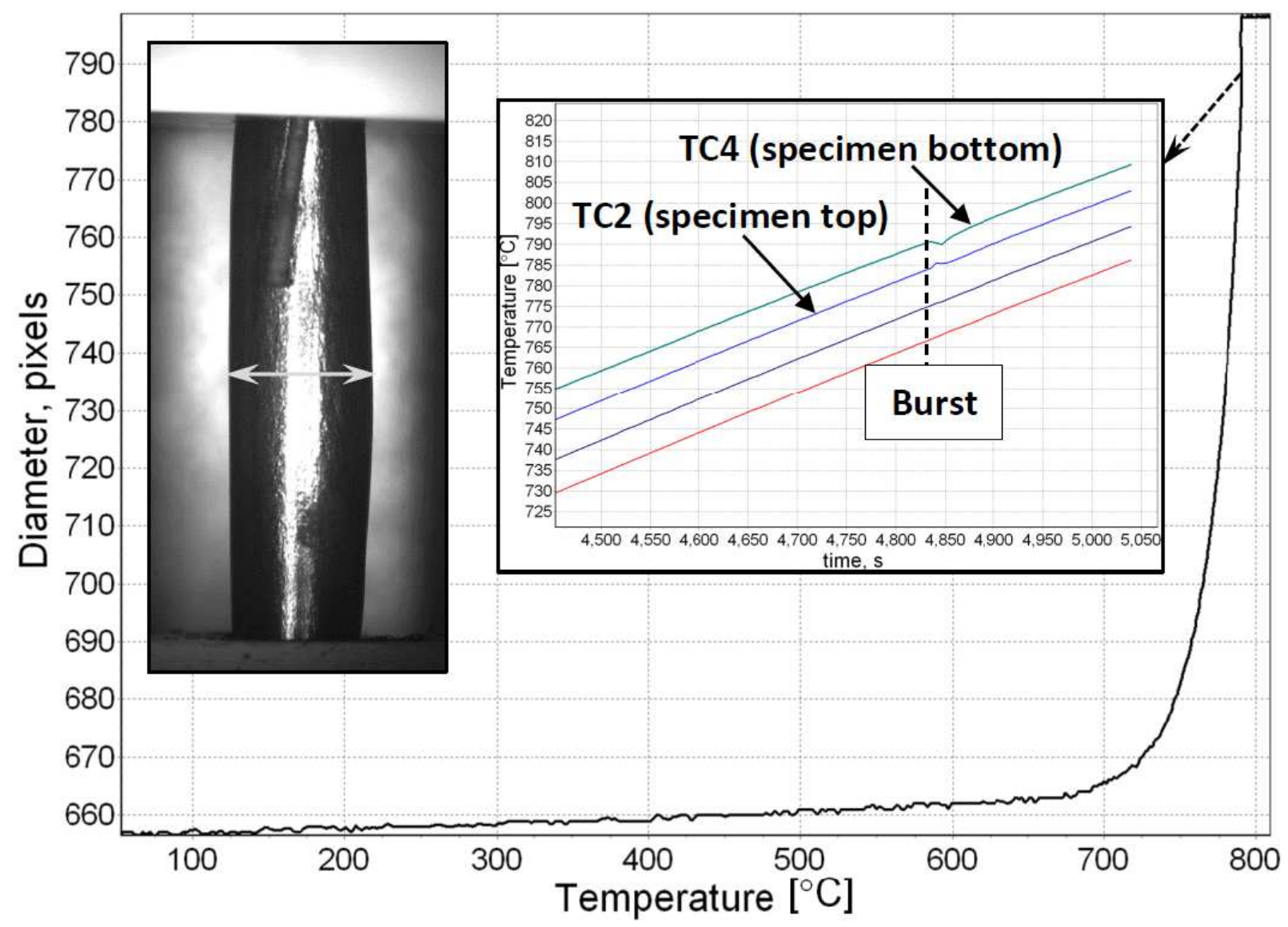

Figure 4. Specimen diameter (pixels) versus temperature for the location with the highest strain level (T35Y alloy). The inset shows a portion of thermocouple readings showing an impact or a small change at specimen burst. 
Using the in-situ images, specimen diameter can be measured at any location over the specimen length. Data were recorded from 10-12 locations along the tube length every 1 to 5 seconds. The black line in Figure 4 displays the specimen diameter change in pixels at the location of maximum strain. The relative diameter increase (\%), which is a nominal strain that can be converted from the pixel data in Figure 4, is displayed in Figure 5. This data also can be defined as the nominal hoop strain. Note that the true strain is slightly smaller than the nominal strain, as a logarithm is applied to the nominal value. This curve shows that the plastic deformation starts to increase around $700^{\circ} \mathrm{C}$, before which diametral change is small and nearly linear and is the result of thermal expansion and elastic strain due to internal pressure. Figure 5 also illustrates the noise level in diameter data, which is more visible in the temperature range from room temperature to $650^{\circ} \mathrm{C}$. It is worth noting, however, that the total noise in reading, which comprises the majority of the accuracy limitation in the test, was below $\sim 0.2 \%$.

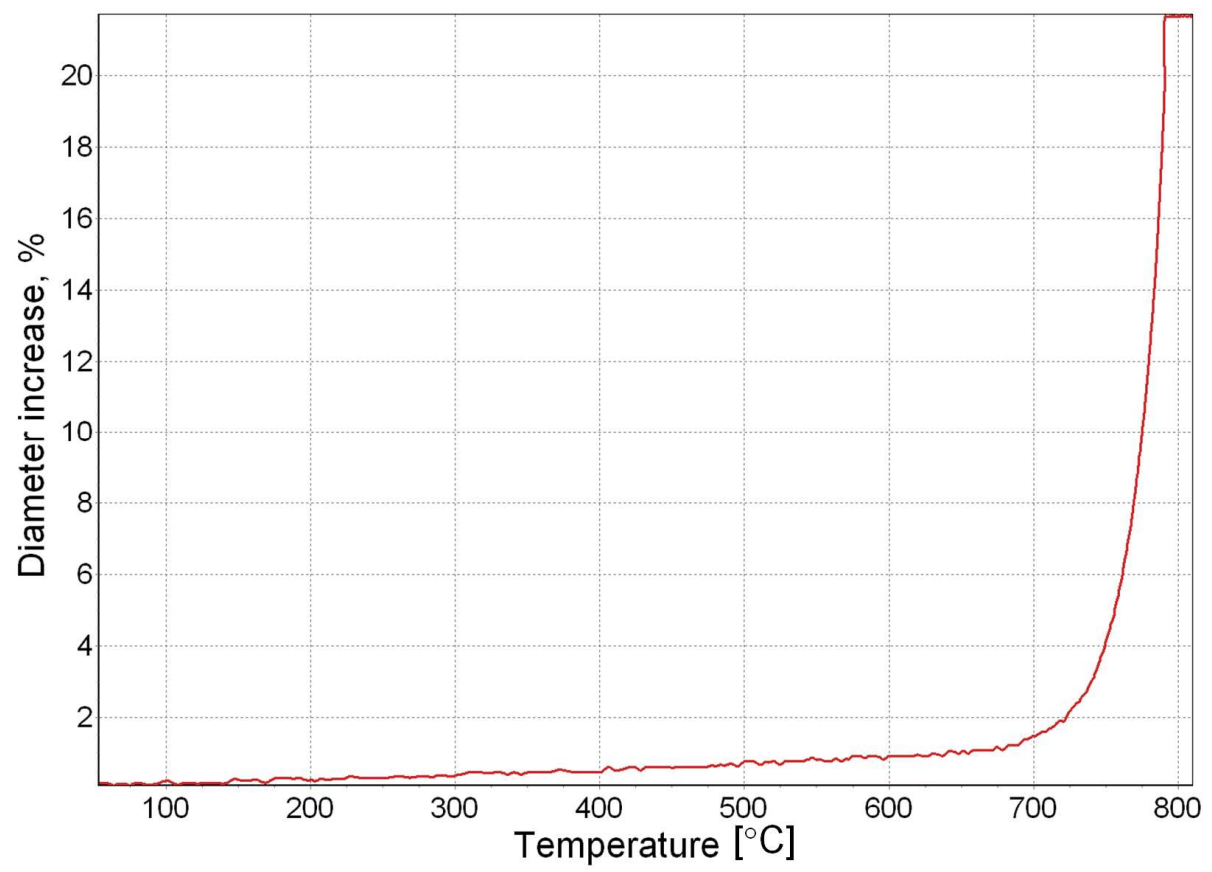

Figure 5. Diameter increase (\% of the initial specimen diameter) in T35Y alloy as a function of temperature (TC2 thermocouple). 
Table 2 summarizes the 12 tests with materials and their deformation and/or burst data. It is worth noting that very close burst data from the two T35Y alloy specimens confirms the reproducibility of the test method. Among the 12 tests, the heating durations were spread over the range of 2.5 to 5 hours, which depended on whether the test specimen could fail by deformation in the course of heating or not. Such a wide range of test durations with the same initial internal pressure was because the new high strength materials did not initiate plastic deformation on heating up to the limit of furnace capacity $\left(\sim 1100^{\circ} \mathrm{C}\right)$ with the initial pressure 2.07 $\mathrm{MPa}$. After either a specimen failed or the temperature reached the furnace limit, the system was stopped and allowed to cool down before the next specimen was tested.

As indicated by the burst data in Table 2, only four specimens (three materials) demonstrated significant plastic deformation followed by a burst during heating to near $1100^{\circ} \mathrm{C}$. Other specimens experienced little deformation, although the tubular specimens, except for the B-T35Y2 without pressure, were pressurized to the same value. Such a stark difference in deformation-burst behavior should result primarily from their strength difference and, to a lesser degree, from the difference in their wall thicknesses, as will be confirmed in the last section.

For these burst specimens, the swelling-start temperatures could be determined using images recorded during the tests, and then the burst temperature determined soon thereafter. In the pressurized specimens, the initial room temperature gas pressure was set at $2.07 \mathrm{MPa}(\sim 20$ atm), and the internal pressure might increase by 3-4 times at the burst temperatures according to the gas law. At the time of the burst, which is usually the occurrence of a small opening, the discharging gas can expand its volume dramatically, which can generate a jet flow or turbulence around the nearby thermocouples, and therefore a small change of temperature reading can be detected. Another obvious indication of burst is that the diameter increase of the specimen will stop as the stress in the tube wall is released. Therefore, there are two ways to detect the burst and determine tube failure temperature using the recorded data: by observing the small temperature change at the burst and by termination of diametral change with further temperature increase, as indicated in Figure 4. 
Table 2. Summary of test results: dimensional changes and temperature parameters

\begin{tabular}{|c|c|c|c|c|c|c|}
\hline Alloy Type & Specimen & $\begin{array}{c}\text { Initial } \\
\text { Diameter } \\
{[\mathrm{mm}]}\end{array}$ & $\begin{array}{l}\text { Initial } \\
\text { Thickness } \\
\text { [mm] }\end{array}$ & $\begin{array}{c}\text { Maximum } \\
\text { Post-test } \\
\text { Diameter }[\mathrm{mm}]\end{array}$ & $\begin{array}{c}\text { Ballooning } \\
\text { Start } \\
\text { Temp. }\left[{ }^{\circ} \mathrm{C}\right]\end{array}$ & $\begin{array}{c}\text { Failure } \\
\text { (Burst) } \\
\text { Temp. [C] }\end{array}$ \\
\hline \multirow{7}{*}{ Fe-Cr-Al Alloy } & Kanthal-AF & 10.34 & 0.37 & 11.03 & 580 & 746 \\
\hline & T35Y-1 & 9.53 & 0.50 & 11.51 & 650 & 790 \\
\hline & T35Y-2 & 9.52 & 0.50 & 10.65 & 660 & 775 \\
\hline & C35MN5 & 9.51 & 0.50 & 9.51 & $>975$ & $\mathrm{n} / \mathrm{a}$ \\
\hline & C35MN6 & 9.54 & 0.50 & 9.54 & $>1038$ & $\mathrm{n} / \mathrm{a}$ \\
\hline & A-T35Y2 & 9.51 & 0.37 & 13.14 & 627 & 745 \\
\hline & B-T35Y2* & 9.51 & 0.37 & 9.54 & $>1054$ & $\mathrm{n} / \mathrm{a}$ \\
\hline \multirow{2}{*}{$\begin{array}{l}\text { Advanced } \\
\text { ODS Fe-Cr-Al } \\
\text { Alloy }\end{array}$} & D155YT & 9.53 & 0.50 & 9.54 & $>1030$ & $\mathrm{n} / \mathrm{a}$ \\
\hline & D155YMT & 9.52 & 0.52 & 9.55 & $>1050$ & $\mathrm{n} / \mathrm{a}$ \\
\hline \multirow{3}{*}{$\begin{array}{l}\text { Advanced } \\
\text { ODS Fe-Cr-W } \\
\text { Alloy }\end{array}$} & 9YWTV-PM1 & 10.21 & 0.59 & 10.22 & $>1030$ & $\mathrm{n} / \mathrm{a}$ \\
\hline & 9YWTV-PM2 & 10.21 & 0.69 & 10.25 & $>1085$ & $\mathrm{n} / \mathrm{a}$ \\
\hline & 14YWT-CRT & 10.2 & 0.63 & 10.2 & $>1070$ & $\mathrm{n} / \mathrm{a}$ \\
\hline
\end{tabular}

(*not pressurized)

For final dimension data, diametral change was measured after each test by physical contact. The specimen cross-sectional shape was close to circular for all specimens, including those that experienced ballooning, and therefore the tube diameters measured at different tangential locations were well within $<3 \%$ variation. On the other hand, since the plastic strain and diametral change were strongly inhomogeneous along the length direction, as seen in Figure 2 , only the largest diameter measurement was converted to the maximum hoop strain for further calculation and discussion. Details are provided in the following sections.

\subsection{Maximum diameter and hoop strain}

The outer diameter data, which were converted from the numbers of pixels at the middle of tubular specimens, are compared in Figure 6. Although the pixels across the diameter were counted at 10 to12 equally spaced longitudinal locations on each tubular specimen, the stress and strain analyses were focused on the behavior at the middle (i.e., maximum diameter) position. 
Note that the overall resolution limit in the dimensional measurements is $\sim 12 \mu \mathrm{m}$ for the present optical procedure. In Figure 6, the burst and intact specimens demonstrate different shapes of curves: the outer diameters of all tested specimens are nearly flat up to about $650^{\circ} \mathrm{C}$, the four curves for T35Y-1 \& -2, A-T35Y2, and Kanthal-AF start to deviate from their linear portions and rapidly increase in the $600-800^{\circ} \mathrm{C}$ range until failure, while the curves of other specimens remain nearly flat up to the maximum test temperature near $1100^{\circ} \mathrm{C}$.

The ballooned and burst specimens were made of relatively soft materials and thin-walled tubes. The highest maximum diametral expansion, $\sim 3.5 \mathrm{~mm}$, was observed on the specimen AT45Y2, and no specimens expanded more than a few millimeters. The diameters remain unchanged after burst, as no further deformation can be induced after the deflation. A high reproducibility in the diameter-temperature data is notable as the two T35Y specimen curves are nearly identical up to the final burst of T35Y-2. Regardless of such high reproducibility, the formation of a through-thickness crack may be highly dependent on the local microstructure and surface morphology around the middle section of a specimen, and therefore the rupture diameters should show large scattering and could be significantly different for the same alloy. It is also notable that the tube burst, i.e., ballooning and failure, occurs within a narrow range of temperature. Once the plastic (creep) deformation is initiated, the final failure occurs within a $<200^{\circ} \mathrm{C}$ increase.

The true hoop strains could be easily calculated from the diametral change and are compared in Figure 7 for all test alloys. Again, the maximum strain, $\sim 0.32$, was obtained for alloy A-T35Y2, and the other three swollen specimens showed true strains less than 0.2 . The other specimens, showing only straight lines, are relatively higher strength and/or thicker specimens. The total strain for these cases comprises thermal expansion strain and pressureinduced elastic strain only, and hence the slopes of the curves for these nil-plasticity specimens are nearly negligible when compared to those of specimens that underwent creep. 


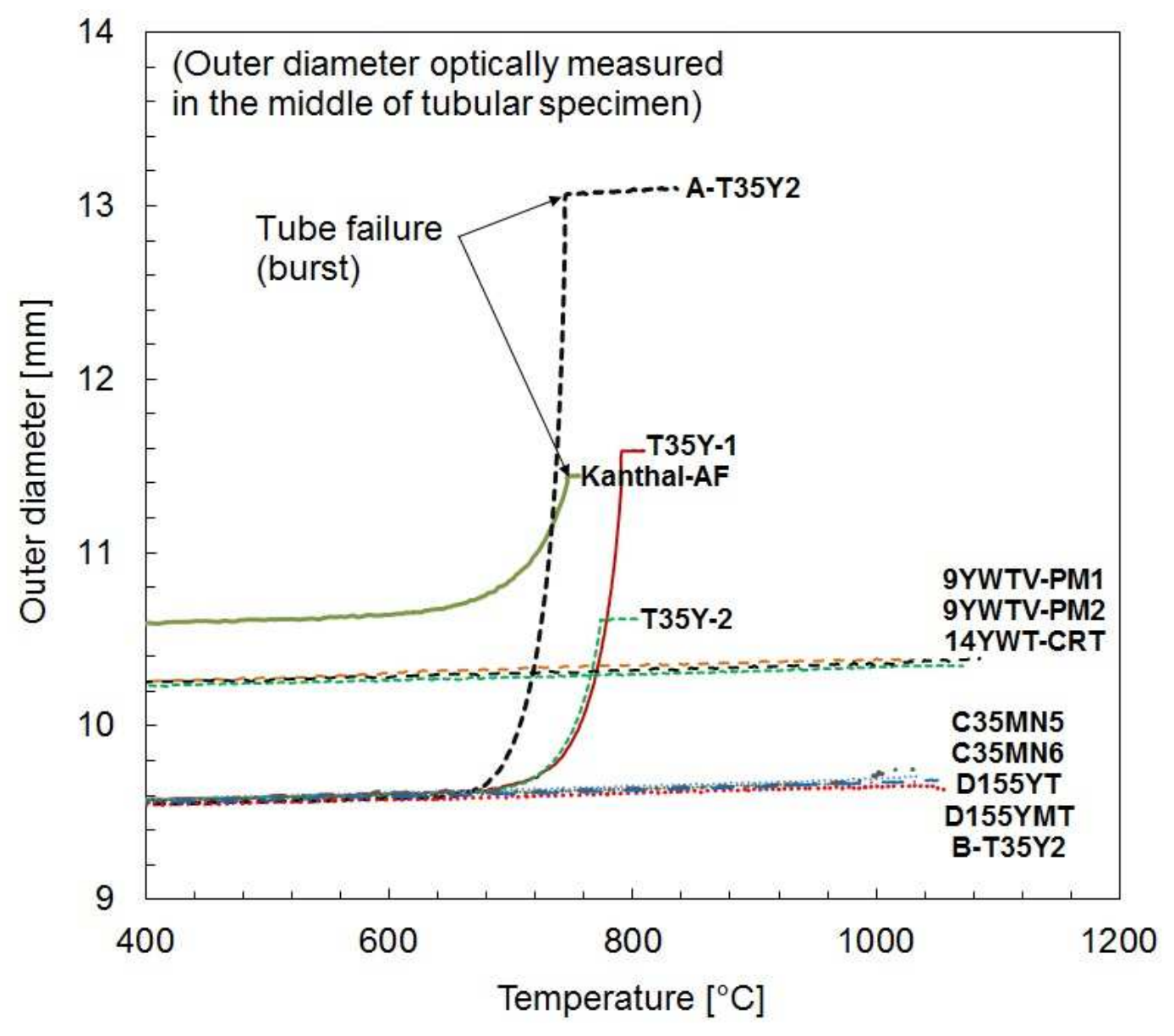

Figure 6. Temperature dependence of outer diameter converted from optical measurements, i.e., the number of pixels across the specimen diameter. 


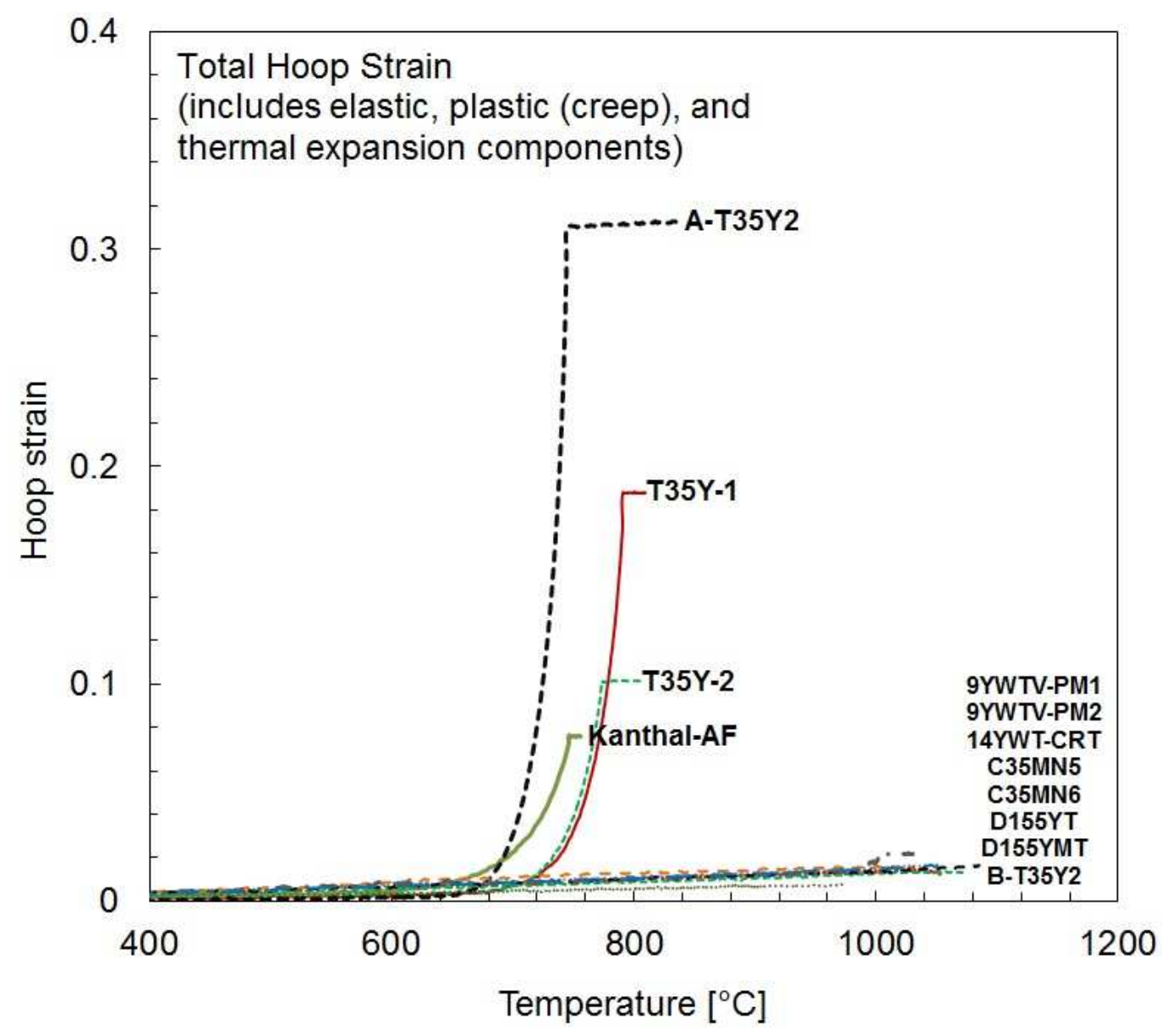

Figure 7. Temperature dependence of hoop strain. The true strain values were calculated from the outer diameters of specimens.

\subsection{Internal pressure and true hoop stress}

The internal pressure-versus-temperature curves are displayed in Figure 8. The internal pressure during heating was calculated using the gas law (Boyle's law). The volume of a heated tubular specimen was calculated from the average of diametral measurements on the equally spaced points over the length of the specimen. Since the initial gas pressures were set at the same value of $2.07 \mathrm{MPa}$ and the pressure increase is caused mostly by gas expansion, the internal pressure during heating was linearly proportional to the gas temperature until plastic deformation became significant. In Figure 8, the closely spaced linear lines indicate that the thermal expansion and elastic deformation have very minor differences among these specimens. 
As with the curves of diameter and strain versus temperature in Figures 6 and 7, Figure 8 indicates that the internal pressure curves of the four $\mathrm{FeCrAl}$ alloy tubes start to deviate from their linear portions above $600^{\circ} \mathrm{C}$, while the thicker and/or stronger specimens experienced no plastic deformation within the test temperature range $\left(<1100^{\circ} \mathrm{C}\right)$. It is notable that the tube burst, i.e., ballooning and failure, occurs within a $<200^{\circ} \mathrm{C}$ increase.

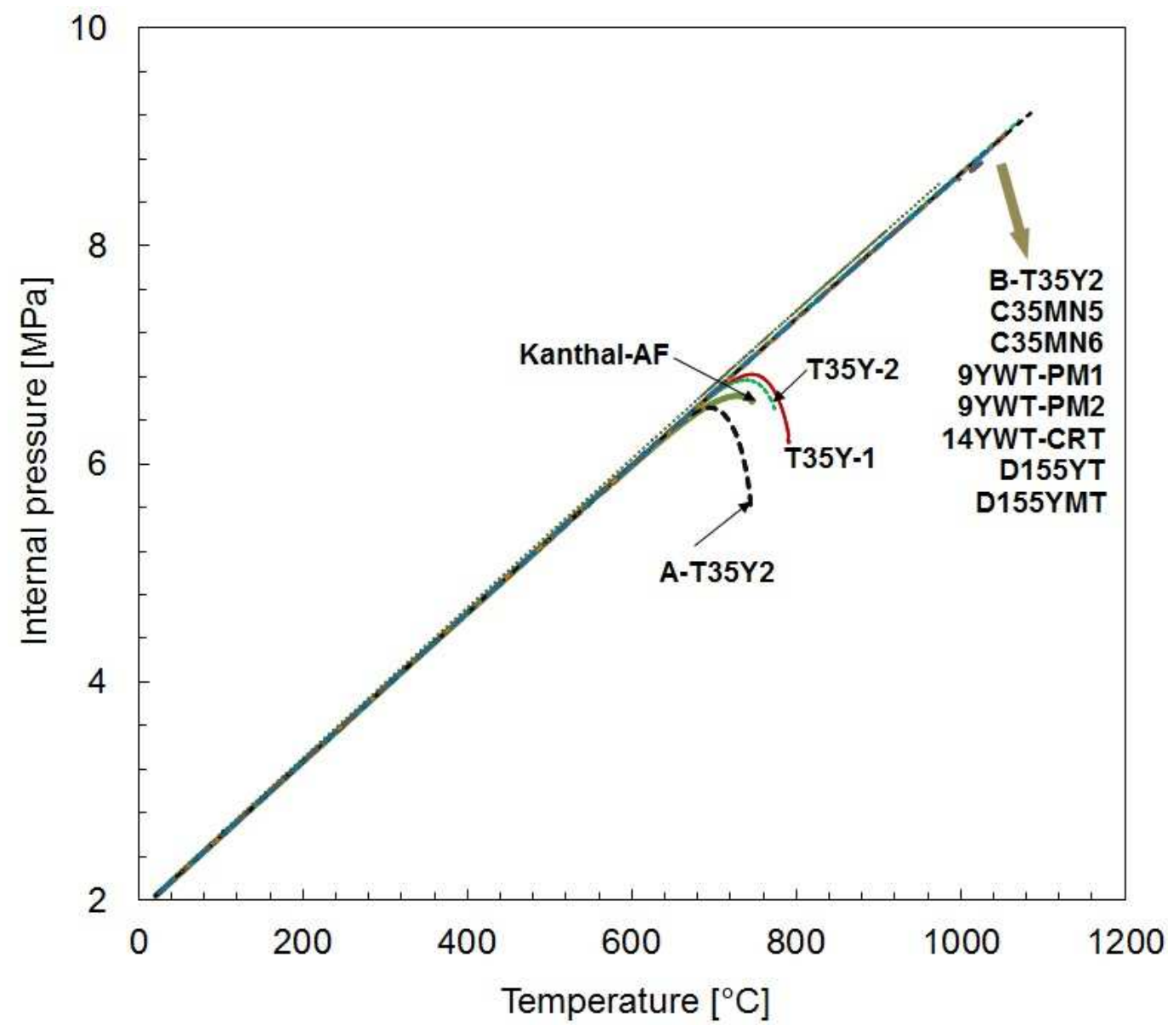

Figure 8. Internal pressure versus temperature curves. The internal pressure is almost purely dependent on the thermal expansion of helium gas in the tubular specimens. Deviation of curves from linearity is a result of the ballooning or internal volume expansion of the pressurized tubular specimens.

Although the internal gas pressure that increases with temperature is the main force for inducing plastic deformation, the initiation and rate of plastic strain is determined by actual stress in the walls of tubular specimens. The internal pressure data in Figure 8 were converted to the 
true hoop stress at the maximum diameter location using the wall thickness data calculated with the constant volume assumption in plastic deformation; results are shown in Figure 9. Due mostly to the difference in initial wall thickness, the hoop stresses were significantly different among the material groups: all of the $\mathrm{FeCrAl}, \mathrm{Fe}-9 \mathrm{Cr}$, and $\mathrm{Fe}-14 \mathrm{Cr}$ ODS alloys were subjected to relatively low hoop stress, and consequently no creep deformation was induced for those alloys. For the specimens that swelled, the internal pressure and true hoop stress behaved in opposite ways: during ballooning, the true hoop stress in the wall increased as the internal pressure decreased.

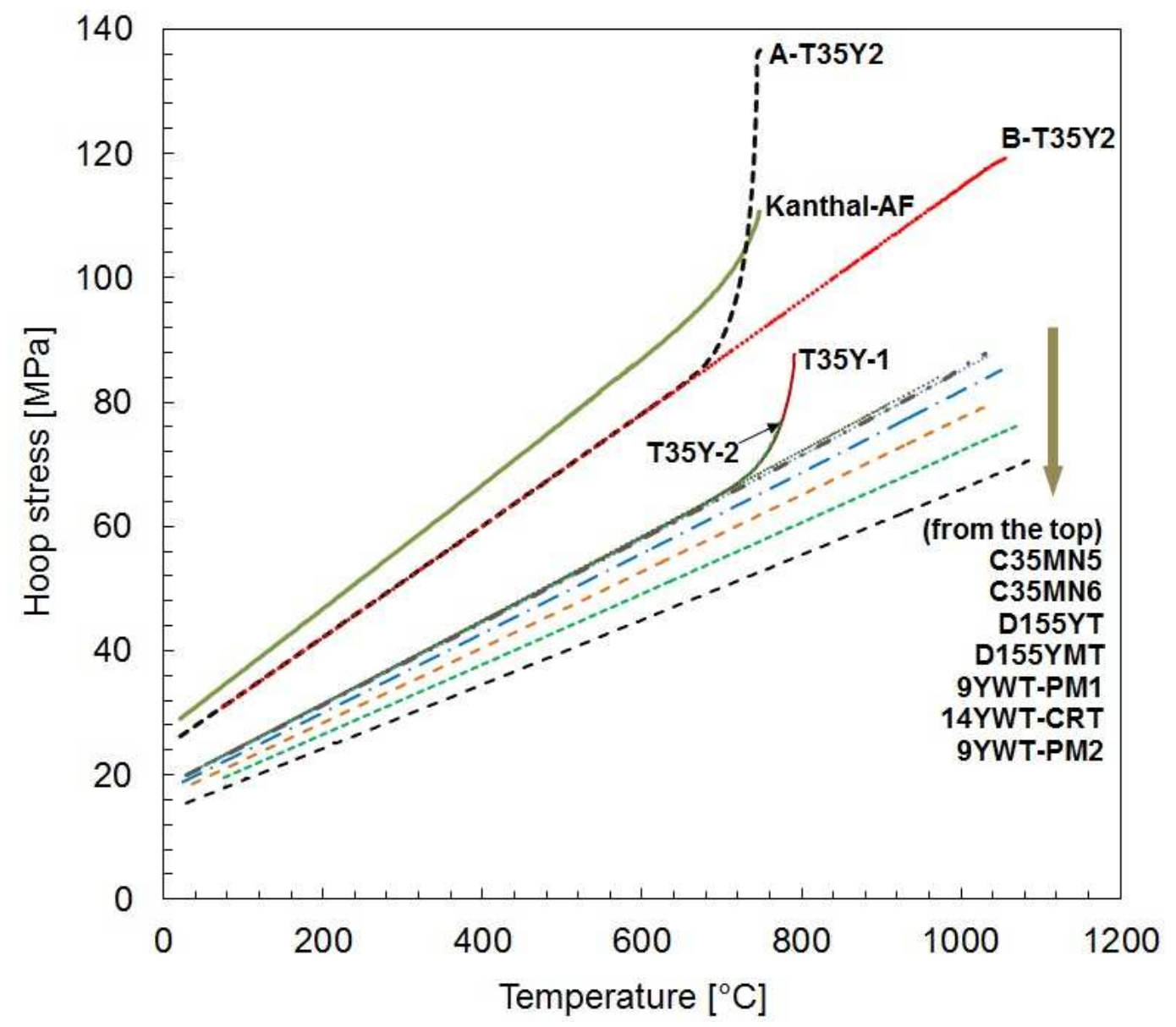

Figure 9. Temperature dependence of hoop stress in the walls of tubular specimens. The differences in wall thickness and diameter resulted in significantly different hoop stresses. 


\subsection{High-temperature plastic (creep) deformation behavior}

The most unique output of the present in-situ testing method may be the in-situ creep rate data from swelling tube specimens. In fuel behavior analysis under accident conditions, the creep test data, which usually are obtained through multiple static creep or low-speed tensile tests, have been used as input for the constitutive equation of high-temperature deformation [2,3,25]. Such an approach of using static test data, however, may not correctly simulate the actual "dynamic" cladding deformation under biaxial loading, because the most important controlling parameters for deformation, i.e., temperature and true stress, continue to increase during a LOCA. The typical primary-steady-tertiary creep stages cannot be defined, but the creep curve may be described by a transition from consecutive primary creep stages in a relatively low temperature region to nearly "instant" plastic deformation just before rupture. As it is intended, the present in-situ testing method can provide the strain rate data under such constantly changing conditions. For the specimens that ballooned and ruptured, the hoop strain rates were calculated and are displayed in Figure 10. Note that the non-permanent deformation, such as thermal expansion and elastic deformation, is much smaller than the permanent (plastic) deformation: at a heating rate of $\sim 10^{\circ} \mathrm{C} / \mathrm{s}$, for example, the non-permanent strain increased at a rate of $\sim 1 \times 10^{-6} \mathrm{~s}^{-1}$.

A few unique behaviors can be found from these strain (creep) rate data, which might originate from the fact that the transitional deformation in a simulated accident condition differs significantly from results of static creep or tensile testing under fixed conditions. First, the strain rate on a logarithmic scale increases almost linearly with test temperature. This indicates that the creep or plastic deformation rapidly accelerates with temperature, which is because the increasing temperature lowers the strength of materials but increases internal gas pressure. Further, the reduction in thickness with deformation should contribute significantly to the increase in strain rate.

Second, the strain rate measurements range from $10^{-6} \mathrm{~s}^{-1}$ to $10^{-3} \mathrm{~s}^{-1}$. Such a significant increase in strain rate confirms that the plastic deformation during heating at a nominal heating rate of $\sim 10^{\circ} \mathrm{C} / \mathrm{s}$ has started at a rate of slow (creep) deformation but ended at a rate that is typical of static tensile testing at burst temperature. The majority of plastic strain to burst should result from the quasi-static plastic deformation, as in a low strain rate tensile test. 
Third, the slope of the strain rate in the semi-log curve is lower for the Kanthal-AF tube compared to those of the other three specimens (T35Y-1, T35Y-2, and A-T35Y2), which all show similar slopes. Also, the creep strain in Kanthal-AF starts to increase at a relatively low temperature of $\sim 610^{\circ} \mathrm{C}$, but the creep deformation ends at the lowest value $(6.7 \%)$ of all the burst FeCrAl specimens, as shown in Figure 7. A cause for these differences in creep rates could be the difference in their chemistries, which can result in different elemental diffusivities and carbide precipitation strengths: the Kanthal-AF has $21 \mathrm{wt} . \%$ chromium in it and the others have $\sim 13$ wt.\%. It has been shown that in Fe-Cr steels, the resistance to creep rupture decreases with increasing chromium content from the peak at $\sim 10 \%$ chromium, although the effect of chromium on the creep rupture strength becomes complex in commercial steels as it forms various carbides under the influence of other alloying elements [26].

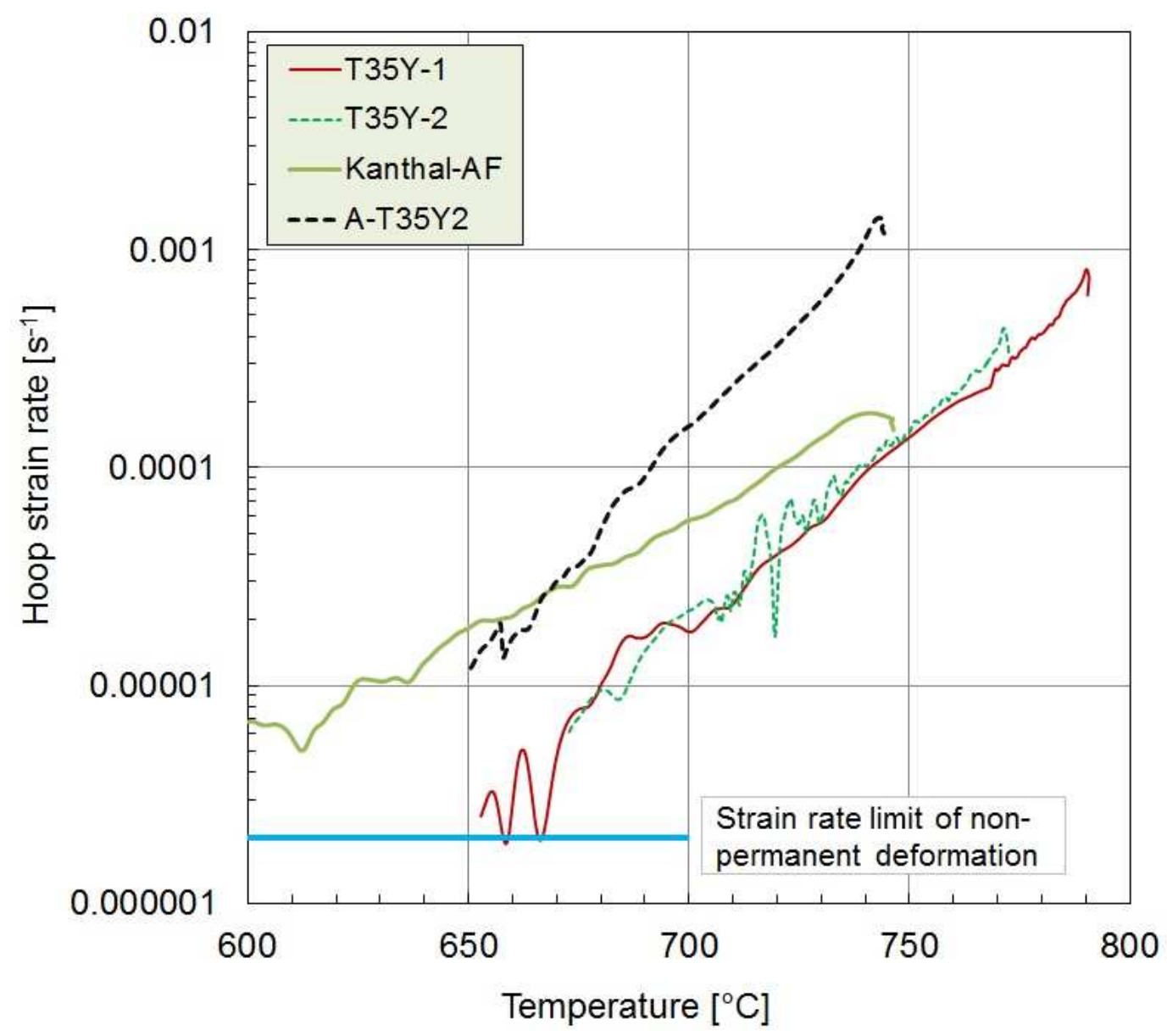

Figure 10. Creep rate versus temperature curves for relatively soft FeCrAl alloys: T35Y, Kanthal-AF, and A-T35Y2. 
The significant difference in strain rate $(\varepsilon)$ behavior should be reflected in the creep parameters, such as activation energy $(Q)$ and stress exponent $(n)$, when the creep rate data are fitted into a general form of the creep equation [27,28]:

$$
\dot{\varepsilon}^{\prime}=A \sigma^{n} \exp \left(\frac{-Q}{R T}\right), \quad \text { (Eq. 1) }
$$

where $A$ is the coefficient determined by the diffusion coefficient $\left(D_{o}\right)$ and the elastic modulus $(G)$ and $R$ is the gas constant, $8.314 \mathrm{~J} /(\mathrm{K} \cdot \mathrm{mole})$. Table 3 lists the coefficients for the four ruptured specimens obtained by an iterative curve-fitting process. The values of stress exponent $(n)$ are in a relatively narrow range of 2.9-4.5, which are relatively low values but fall well inside the range for dislocation creep in metallic materials (i.e., 3-8) [28]. The activation energy $(Q)$ obtained for the $13 \mathrm{Cr}$ alloys is commonly about $250 \mathrm{~kJ} / \mathrm{mole}$, while the $21 \mathrm{Cr}$ alloy shows a much lower value, $143 \mathrm{~kJ} / \mathrm{mole}$. For this Kanthal-AF case, the earlier start of deformation during heating can be explained by such low activation energy. It is also noted that the Kanthal-AF has the highest stress exponent, and the highest stress sensitivity has resulted in relatively low rupture strain $(<10 \%)$.

Table 3. Summary of creep parameters

\begin{tabular}{|l|c|c|c|}
\hline Alloy & $\begin{array}{c}\text { Stress } \\
\text { Exponent } n\end{array}$ & $\begin{array}{c}\text { Activation Energy } \\
{[\mathrm{kJ} / \mathrm{mole}]}\end{array}$ & $\begin{array}{c}\text { Coefficient } A \\
{\left[\mathrm{~s}^{-1}\right]}\end{array}$ \\
\hline T35Y-1 & 3.7 & 248 & 82 \\
\hline T35Y-2 & 3.9 & 254 & 84 \\
\hline Kanthal-AF & 4.5 & 143 & $2.9 \times 10^{-6}$ \\
\hline A-T35Y2 & 2.9 & 258 & $2.2 \times 10^{+4}$ \\
\hline
\end{tabular}

Lastly, as shown in the above discussion, the traditional dislocation creep model (Eq. 1) could successfully describe the creep deformation behavior of tubular specimens during the simulated accident conditions. Assuming that the single mechanism of dislocation glide has yielded total plastic deformation (i.e., constant $Q$ ), the stress coefficient should be the only parameter that describes the unique deformation during an accident, where stress and temperature are constantly changing. As the plastic deformation in the present experiment is 
rather close to a creep test with continuous stress jump, the measured stress exponent values, i.e., 2.9-4.5, are on the lower side of the data range for metallic materials. Elucidating the difference

in those coefficients between the present non-steady-state tube testing and the traditional steadystate creep testing would be interesting, but is beyond the scope of this study.

\subsection{Rupture temperature versus hoop stress with database}

The traditional tube burst testing to measure rupture stress and temperature is a wellestablished method that has helped accumulate a sizable database for fuel cladding materials [714,29]. In Figure 11 the rupture (burst) temperature versus hoop stress data for new alloys are compared to the database for Zircaloy-4, which is a collection of cladding rupture data for a variety of materials and pressurization conditions [29]. The comparison shows that the four values for relatively soft FeCrAl alloys, i.e., T35Y, Kanthal-AF, and T35Y2, fall within the band of Zircaloy data. The tubular specimens of the other alloys with higher strength experienced little plastic deformation and no rupture before heating was stopped and, as indicated in Figure 11, their rupture temperatures are expected to be higher than $1100^{\circ} \mathrm{C}$.

During a postulated LOCA, the reactor coolant pressure may drop below the internal fuel rod gas pressure and cause the fuel cladding to swell and rupture in some conditions [4,25,29]. The severity of the accident would determine core structure behavior such as the time at which swelling and rupture occur, the magnitude of swelling, the resulting coolant flow blockage, and the eventual release of fuel fragments and fission products. Although having many unruptured specimens is one shortcoming in the present burst experiment, the data can be still used to demonstrate that a fuel cladding with higher strength can suppress plastic deformation and delay rupture during accidents. This can lead to maintaining fuel channel cooling capability for longer periods of time and, more importantly, result in release of less fuel material. That is, the high strength itself offers more accident tolerance. 


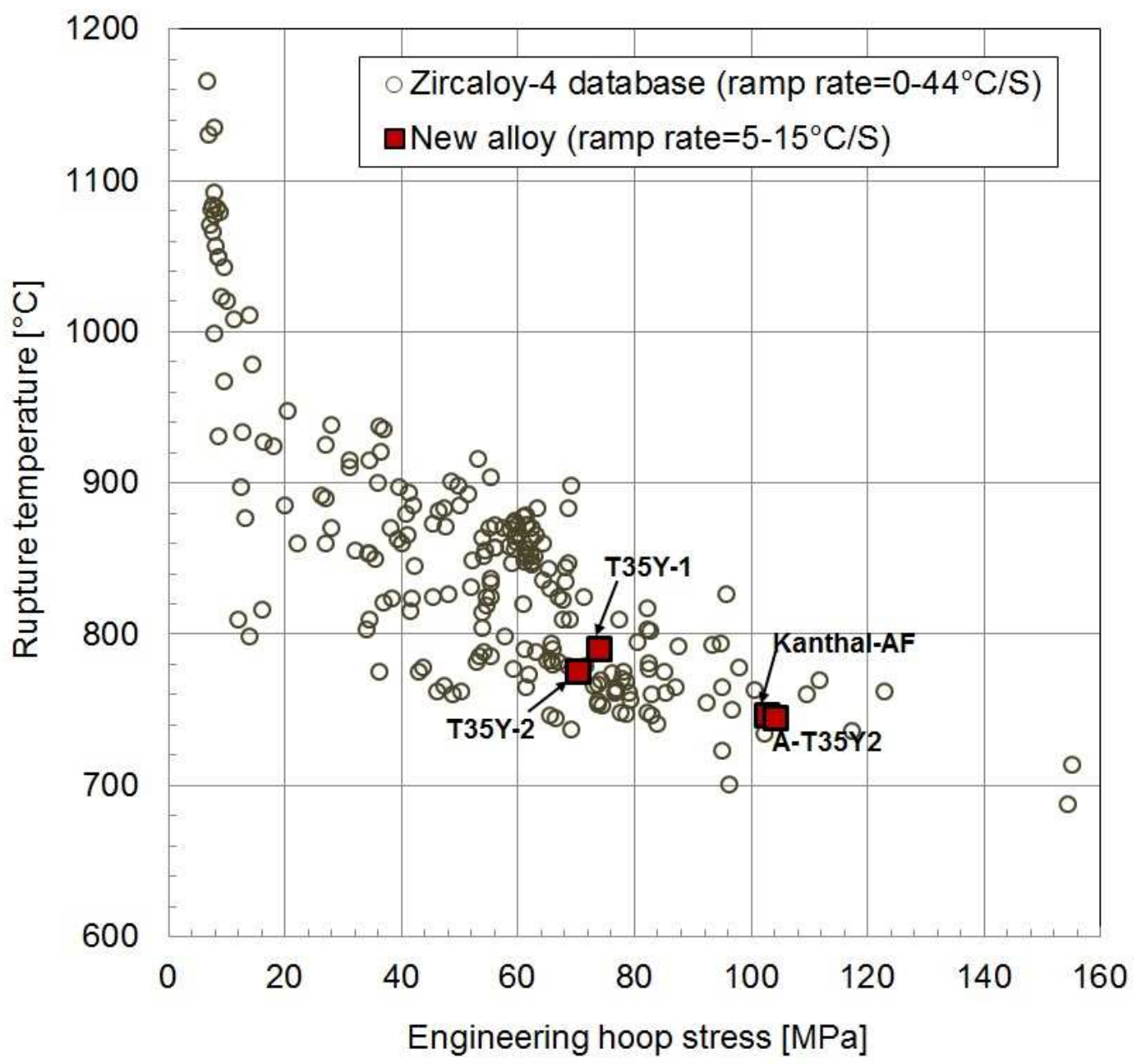

Figure 11. Comparison of rupture temperature versus hoop stress data. The Zircaloy-4 database is from reference [29], which integrates the results of tube burst tests by multiple international institutes.

\section{Summary and conclusions}

(1) To investigate the mechanical behaviors of fuel cladding materials in simulated LOCA conditions, an in-situ deformation and burst testing method has been developed on the basis of visual imaging and image analysis techniques. The new method uses a specialized optics system consisting of a high-resolution video camera, a light filtering unit, and monochromatic LED light sources, and tests a $50 \mathrm{~mm}$ long pressurized thin-walled tube specimen.

(2) The testing system and pressurized tubular specimen were designed to enable inexpensive and convenient irradiation experiments and laboratory testing. This in-situ dimensional 
measurement method aims to provide in-situ strain and stress data and, more importantly, creep rate data that is needed in the assessment of fuel performance.

(3) High-temperature tube deformation and burst testing has been performed for 10 candidate ATF cladding materials. The pressurized thin-walled tube specimens of FeCrAl alloys, ODS FeCrAl alloys, and NFAs 14YWT and 9YWTV were fabricated using various material processing techniques, and endcaps were laser welded in a pressurized chamber.

(4) One commercial FeCrAl alloy (Kanthal-AF) and two newly developed FeCrAl alloys (T35Y and A-T35Y2) deformed to significant hoop strain levels and burst-failed at temperatures in the range $740-800^{\circ} \mathrm{C}$. The burst temperature data from those soft $\mathrm{FeCrAl}$ alloys are well within the range of the database for Zircaloy. In contrast, all the ODS/NFA alloys and two new FeCrAl alloys (C35MN5 and C35MN6) with extra strengthening mechanisms and thicker tube walls showed little change in diameter and did not fail before the furnace limit temperature $\left(1100^{\circ} \mathrm{C}\right)$ was reached.

(5) Such a dramatic difference between the burst failure behaviors of relatively soft and hard alloys indicates that some high strength ATF cladding materials can significantly improve the cooling efficiency in fuel channels during a LOCA by keeping the channels open for a longer period of time.

(6) For the FeCrAl alloys, the traditional dislocation creep model based on power-law stress dependence and Arrhenius-type thermal dependence could successfully describe the creep deformation behavior of tubular specimens during the simulated accident conditions.

\section{Acknowledgments}

This research has been carried out in multiple national laboratories and was sponsored by the Fuel Cycle R\&D program of the Office of Nuclear Energy, U.S. Department of Energy. The authors would like to express special thanks to Drs. R. Montgomery and M. Toloczko of Pacific Northwest National Laboratory for their technical reviews and thoughtful comments. 


\section{References}

[1] D. Olander, J. Nucl. Mater. 389 (2009) 1-22.

[2] C.R.F. Azevedo, Eng. Failure Analysis 18 (2011) 1943-1962.

[3] K.T. Kim, Nucl. Eng. Des. 263 (2013) 59-69.

[4] T. Alam, M.K. Khan, M. Pathak, K. Ravi, R. Singh, S.K. Gupta, Nucl. Eng. Des. 241 (2011) 3658-3677.

[5] K.A. Terrani, S.J. Zinkle, L.L. Snead, J. Nucl. Mater. 448 (2014) 420-435.

[6] S.J. Zinkle, K.A. Terrani, J.C. Gehin, L.J. Ott, L.L. Snead, J. Nucl. Mater. 448 (2014) 374379.

[7] A. Bauer, L.M. Lowry, W.J. Gallaghar, ASTM-STP 681 (1979) 465-476.

[8] R.H. Chapman, J.L. Crowley, A.W. Longest, G. Hofmann, ASTM-STP 681 (1979) 393408.

[9] H.M. Chung, A.M. Garde, T.F. Kassner, ASTM-STP 633 (1977) 82-97.

[10] F. Erbacher, H.J. Neitzel, K. Weihr, ASTM-STP 681 (1977) 429-446.

[11] F.J. Erbacher, H.J. Neitzel, H. Rosinger, H. Schmidt, K. Weihr, ASTM-STP 754 (1082) 271-283.

[12] F.J. Erbacher, S. Leistikow, ASTM-STP 939 (1987) 451-488.

[13] W.A. Fiveland, A.R. Barber, A.L. Lowe Jr., ASTM-STP 633 (1977) 36-49.

[14] M.E. Markiewicz, F.J. Erbacher, Experiment on Ballooning in Pressurized and Transiently Heated Zircaloy-4 Tubes, Kernforschungszentrum Kalrsruhe, KfK4343 (1988).

[15] T.K. Sawarn, S. Banerjee, K.M. Pandit, S. Anantharaman, Nucl. Eng. Des. 280 (2014) 501-510.

[16] J.M. Ricaud, N. Seiler, G. Guillard, Nucl. Eng. Des. 256 (2013) 45-55.

[17] L.H. Alva, X. Huang, G.M. Jacobsen, C.A. Back, High Pressure Burst Testing of SiCfSiCm Composite Nuclear Fuel Cladding, in Conference Proceedings of the Society for Experimental Mechanics Series, 2015.

[18] J.S. Lyons, J. Liu and M.A. Sutton, Exper. Mech. 36 (1996) 64-70.

[19] B.M.B. Grant, H.J. Stone, P.J. Withers, M. Preuss, J. Strain Ana. for Eng. Des. 44 (2009) 263-271.

[20] B. Pan, D. Wu, Z. Wang, Y. Xia, Measurement Sci. Tech. 22 (2011) 015701.

[21] M.D. Novak, F.W. Zok, Review of Sci. Instrum. 82 (2011) 115101.

[22] X. Chen, L. Yang, N. Xu, X. Xie, B. Sia, R. Xu, Optics \& Laser Tech. 57 (2014) 318-326.

[23] X. Guo, J. Liang, Z. Tang, B. Cao, M. Yu, Optical Eng. 53 (2014) 063101.

[24] A.H. de Menibus, Q. Auzoux, P. Mongabure, V. Macdonald, T. Le Jolu, J. Besson, J. Crepin, Mater. Sci. Engi. A 604 (2014) 57-66.

[25] T. Manngård, A.R. Massih, Modelling of nuclear fuel cladding under loss-of-coolant accident conditions, Report \#2013:24 (ISSN: 2000-0456), Swedish Radiation Safety Authority (July 2013) (www.stralsakerhetsmyndigheten.se).

[26] T. Fujita, K. Asakura, H. Miyake, Trans. ISIJ 22 (1982) 13-21.

[27] S.L. Robertson, O.D. Sherby, Acta Met. 17 (1969) 109-125.

[28] G.E. Dieter, Mechanical Metallurgy, $3^{\text {rd }}$ Ed., McGraw-Hill Book Co., 1986.

[29] D.A. Powers, R.O. Meyer, Cladding swelling and rupture models for LOCA analysis, NUREG-0630, USNRC, April 1980. 